\title{
Effects of resuscitation with crystalloid fluids on cardiac function in patients with severe sepsis
}

\author{
Zhi Xun Fang1, Yu Feng Li ${ }^{2}$, Xiao Qing Zhou ${ }^{3}$, Zhen Zhang4, Jin Song Zhang5, \\ Hai Ming Xia ${ }^{1}$, Guo Ping Xing ${ }^{3}$, Wei Ping Shu ${ }^{1}$, Ling Shen ${ }^{1}$ and Guo \\ Qing Yin*1
}

Address: ${ }^{1}$ The Second Hospital of Nanjing, affiliated with Medical School, Southeast University, 1-1 Zhong-fu Road, Nanjing, Jiangsu, 210003, P.R. China, ${ }^{2}$ The First People's Hospital of Huai'an City, 3 Beijing Road, Huai'an City, Jiangsu, 223300, P.R. China, ${ }^{3}$ The People's Hospital of Gaochun County, Gaochun County, Jiangsu, 211300, P.R China, ${ }^{4}$ The Emergency Department of the First Hospital of Nanjing, affiliated with Nanjing Medical University, 68 Chang-le Road, Nanjing, Jiangsu, 210006, P.R. China and ${ }^{5}$ The Emergency Department of the Jiangsu Province Hospital, affiliated with Nanjing Medical University. 300 Guangzhou Road, Nanjing, Jiangsu, 210029, P.R. China

Email: Zhi Xun Fang - fangzhixun@yahoo.com.cn; Yu Feng Li - liyufeng99@netease.com; Xiao Qing Zhou - zxq@gcph.com.cn; Zhen Zhang - zzlp2000@yahoo.com.cn; Jin Song Zhang - zhangjso@sina.com; Hai Ming Xia - xiahaiming700611@163.com; Guo Ping Xing -wgzx@gcph.com.cn; Wei Ping Shu - swp2008@yeah.net; Ling Shen - najingshl@163.com; Guo Qing Yin* - yinguoq@jlonline.com

* Corresponding author

Published: 17 April 2008

BMC Infectious Diseases 2008, 8:50 doi:10.1 186/147/-2334-8-50

This article is available from: http://www.biomedcentral.com/I47/-2334/8/50

(c) 2008 Fang et al; licensee BioMed Central Ltd.

This is an Open Access article distributed under the terms of the Creative Commons Attribution License (http://creativecommons.org/licenses/by/2.0), which permits unrestricted use, distribution, and reproduction in any medium, provided the original work is properly cited.
Received: 13 July 2007

Accepted: 17 April 2008

\begin{abstract}
Background: The use of hypertonic crystalloid solutions, including sodium chloride and bicarbonate, for treating severe sepsis has been much debated in previous investigations. We have investigated the effects of three crystalloid solutions on fluid resuscitation in severe sepsis patients with hypotension.
\end{abstract}

Methods: Ninety-four severe sepsis patients with hypotension were randomly assigned to three groups. The patients received the following injections within $15 \mathrm{~min}$ at initial treatment: Ns group $(\mathrm{n}=32), 5 \mathrm{ml} / \mathrm{kg}$ normal saline; Hs group $(\mathrm{n}=30)$, with $5 \mathrm{ml} / \mathrm{kg} 3.5 \%$ sodium chloride; and Sb group $(\mathrm{n}=32), 5 \mathrm{ml} / \mathrm{kg} 5 \%$ sodium bicarbonate. Cardiac output $(\mathrm{CO})$, systolic blood pressure, mean arterial pressure (MAP), body temperature, heart rate, respiratory rate and blood gases were measured.

Results: There were no differences among the three groups in CO, MAP, heart rate or respiratory rate during the 120 min trial or the 8 hour follow-up, and no significant differences in observed mortality rate after 28 days. However, improvement of MAP and CO started earlier in the Sb group than in the $\mathrm{Ns}$ and $\mathrm{Hs}$ groups. Sodium bicarbonate increased the base excess but did not alter blood $\mathrm{pH}$, lactic acid or $\left[\mathrm{HCO}_{3}\right]^{-}$values; and neither $3.5 \%$ hypertonic saline nor $5 \%$ sodium bicarbonate altered the $\mathrm{Na}^{+}, \mathrm{K}^{+}, \mathrm{Ca}^{2+}$ or $\mathrm{Cl}$ - levels.

Conclusion: All three crystalloid solutions may be used for initial volume loading in severe sepsis, and sodium bicarbonate confers a limited benefit on humans with severe sepsis.

Trial registration: ISRCTN367483I9. 


\section{Background}

Severe sepsis has been recognized as an increasingly serious clinical problem, accounting for substantial morbidity and mortality. Critical status, organ hypoperfusion, volume deficiency and hypotension characterize its early phase. Therefore, initial care of patients with severe sepsis, such as early volume fluid loading and antibiotic treatment on admission, is emphasized as an early intervention [1-3]. In previous studies, the following benefits of crystalloid fluids have been demonstrated: (1) large-volume resuscitation with isotonic crystalloids conferred the highest survival rates; (2) extracellular fluid was redistributed during shock into both the intravascular and intracellular spaces; and (3) optimal resuscitation to correct this extracellular fluid deficit required infusion of a 3:1 ratio of isotonic crystalloid fluid and blood. Normal saline is the isotonic crystalloid fluid commonly used for volume loading in severe sepsis [2-4].

Small volume resuscitation with hypertonic saline appears to be effective for patients with sepsis or models of experimental severe sepsis [1]. In previous studies, hypertonic saline in dextran improved the hemodynamics of sepsis patients more effectively than an equivalent volume of normal saline [5-7]. Experimental studies in severe sepsis have also shown beneficial effects [8-11]. In rabbits with septic shock, $5 \mathrm{ml} / \mathrm{kg}$ hypertonic (3.5\%) saline without colloid induced a decline in cardiac contractility and a decrease in mean arterial pressure (MAP), and eventually resulted in the death of the animals [12]; whereas in macaque models, the same fluid resuscitation improved myocardial performance $[13,14]$. We believe that hypertonic saline differs in effectiveness between primates and non-primates. Therefore, hypertonic crystalloid resuscitation of severe sepsis patients needs to be investigated in clinical trials.

Sodium bicarbonate has been used clinically for resuscitating sepsis patients, but its efficiency against acidosis and septic shock is the subject of widespread controversy [13-28]. In clinical practice before the 1990s, perfusion with $5 \%$ sodium bicarbonate at $5 \mathrm{ml} / \mathrm{kg}$ was recommended for fluid resuscitation of severe sepsis and septic shock patients [15-19]. The reasons were as follows. (1) Hypoperfusion in a single organ resulted in hypoxia and lactic acidosis in this organ, but the arterial blood $\mathrm{pH}$ might be normal in early septic shock and severe sepsis. Therefore, normal $\mathrm{pH}$ in septic shock did not contraindicate bicarbonate. (2) Acidosis impairs myocardial performance and alters renal blood flow; alkalinized blood might improve cardiovascular performance [20,21]. (3) Hypertonic sodium bicarbonate appeared to be effective for volume replacement. However, it has recently been shown that acidosis might have a protective effect. A low $\mathrm{pH}$ has been shown to delay the onset of cell death, but accelerating $\mathrm{pH}$ correction removes the protective effect and accelerates cell death. Also, acidosis during reperfusion limits the size of myocardial infarctions [22-25]. In experimental investigations of septic shock, sodium bicarbonate aggravated the pathophysiological state in nonprimates such as rats [12], rabbits [26] and ponies [27]. There is no agreement about the use of sodium bicarbonate for treating severe sepsis, and it has not been commonly recommended in clinical practice since the 1990s [28]. However, the effect of sodium bicarbonate in primates is different. We recently demonstrated that administration of sodium bicarbonate improved the performance of the myocardium and normalized the hemodynamic parameters in macaque models $[13,14]$. The macaque model data suggest that $5 \%$ sodium bicarbonate is beneficial in fluid resuscitation during early phase septic shock in primates. We believe that the effects of sodium bicarbonate differ between primates and nonprimates because of the physiological difference between the two types of animals. In view of our findings in macaques, we consider that sodium bicarbonate might be effective for treating severe sepsis and early septic shock in humans because macaques and humans are both primates and are physiologically similar.

The above findings enable us to speculate that crystalloid solutions, whether isotonic normal saline or hypertonic crystalloid fluids, are effective for initial volume loading in severe sepsis, and to consider that the effect of crystalloid solutions on severe sepsis should be assessed. Five percent sodium bicarbonate, with an osmotic pressure of $1190 \mathrm{mOsm} / \mathrm{l}$, is hypertonic. The osmolality of $3.5 \%$ sodium chloride $(1197 \mathrm{mOsm} / \mathrm{l})$ is similar to that of $5 \%$ sodium bicarbonate, and this solution was used to control osmolality in the rabbit and macaque studies $[12,13]$. Therefore, a contrast-randomized clinical protocol of equal volumes $(5 \mathrm{ml} / \mathrm{kg})$ of various solutions, namely normal saline, 5\% sodium bicarbonate and 3.5\% sodium chloride, was designed in the present study.

Over a period of about twenty years, many authors have investigated the physiological signs of septic shock and their treatment [29-34]. Initial treatment of septic patients is critical for ensuring their survival, and therapy for severe sepsis is emphasized as an early intervention. Crystalloid solutions are effective as immediate perfusions for initial volume replacement, but are effective for only 2-3 hours [34]. Our study, therefore, focused on the initial effects of three crystalloid solutions on early-phase severe sepsis, 120 min after the administration of the bolus of fluid.

\section{Methods}

This is a prospective, randomized and multicentric study conducted in five hospitals of Jiangsu Province, China: the Second Hospital of Nanjing, affiliated with Medical 
School of Southeast University; the First People's Hospital of Huai'an City; the People's Hospital of Gaochun County; the Emergency Department of the First Hospital of Nanjing, affiliated with Nanjing Medical University; and the Emergency Department of the Jiangsu Province Hospital, affiliated with Nanjing Medical University. This research was carried out in accordance with the Declaration of Helsinki (2000) of the World Medical Association. The protocol was approved by the Health Office of Jiangsu Provincial Government and by all the hospital ethics committees. Five hundred and thirty-two patients with severe sepsis in these five hospitals were diagnosed between Jun 01, 2001 and Oct 31, 2005, and 94 of the 532 subjects were enrolled in the study.

\section{Enrolment}

Severe sepsis and septic shock were defined according to the criteria reported by Bone and colleagues. Hypotension is determined by a systolic blood pressure lower than 90 $\mathrm{mm} \mathrm{Hg}$ or a reduction of $40 \mathrm{~mm} \mathrm{Hg}$ from baseline. SIRS criteria consist of a suspected sepsis source and two of the four SIRS criteria (temperature $>38^{\circ} \mathrm{C}$ or $<36^{\circ} \mathrm{C}$, heart rate $>90$ beats $/ \mathrm{min}$, respiratory rate $>20$ breaths $/ \mathrm{min}$, $\mathrm{PaCO}_{2}<32 \mathrm{~mm} \mathrm{Hg}$, or white blood cell count $>12,000$ cells per $\mathrm{mm}^{3},<4,000$ cells per $\mathrm{mm}^{3}$, or $>10 \%$ band cells). The status of shock patients may include but is not limited to lactic acidosis, oliguria or an acute alteration in mental state [35].

The criteria for patient enrolment were: (1) hypotension, namely, systolic blood pressure lower than $90 \mathrm{mmHg}$, or MAP lower than $70 \mathrm{mmHg}$, or a reduction of $40 \mathrm{~mm} \mathrm{Hg}$ from baseline; (2) two of four SIRS, or a positive blood culture. Items (1) and (2) were necessary for enrolment.

All the enrolled patients signed informed consent documents within $1 \mathrm{~h}$ of arrival, and child patients had their informed consent documents signed by their guardians.

\section{Exclusion}

Patients with any of the following were excluded: myocardial infarction, hemorrhagic shock, trauma, pregnancy, do-not-attempt-resuscitation orders, requirement for immediate surgery, or death imminent within 24 hours.

In order to focus the study on early phase severe sepsis, patients with final-phase septic shock characterized on admission by coma, seizure, diffuse intravascular coagulation (DIC), pulmonary edema and anuria were rejected. To determine the effect of crystalloid solutions on hemodynamics, cases treated with vasopressors, inotropic agents, colloids and mechanical ventilation during the initial two hours after admission were excluded because those treatments may markedly influence cardiovascular function.

\section{Scores for physiology of patients}

The Acute Physiology and Chronic Health Evaluation (APACHE) II score, Simplified Acute Physiology Score (SAPS) II and Sequential Organ Failure Assessment Score (SOFA) were computed for all the patients from physiological measurements obtained on admission. Expected mortality rates for APACHE II and SAPS II scores were calculated using the logistic regression calculations suggested by Knaus and Le Gall [36-38]. The clinical data are summarized in Table 1.

\section{Program of treatment}

Using a randomized block design, the 94 patients were randomly assigned to three groups. Patients in these groups received the following injections within $15 \mathrm{~min}$ of initial treatment: Ns group $(\mathrm{n}=32), 5 \mathrm{ml} / \mathrm{kg}$ normal saline; Hs group $(\mathrm{n}=30), 5 \mathrm{ml} / \mathrm{kg} 3.5 \%$ sodium chloride; and $\mathrm{Sb}$ group $(\mathrm{n}=32), 5 \mathrm{ml} / \mathrm{kg} 5 \%$ sodium bicarbonate. At $100 \mathrm{~min}$ after $\mathrm{T}_{0}$, all patients were injected with $20 \mathrm{ml} /$ $\mathrm{kg} 0.9 \%$ normal saline. None of the patients received any additional therapy such as vasopressors, colloids or mechanical ventilation within $120 \mathrm{~min}$ of the trial.

At $\mathrm{T}_{120}$ (120 min after $\left.\mathrm{T}_{0}\right)$, all patients were treated according to management guidelines for severe sepsis and septic shock [39]. The therapy that best suited the physiological status of the patient was performed, including administration of vasopressors/inotropics, colloid resuscitation, blood product transfusion or mechanical ventilation. Broad spectrum antibiotics were given to all patients and were altered according to blood culture and sensitivity findings.

\section{Outcome measures}

Cardiac output (CO), systolic blood pressure, mean arterial pressure (MAP), body temperature, heart rate and respiratory rate were measured at the time that fluid resuscitation was started $\left(\mathrm{T}_{0}\right)$; measurements were taken once every $30 \mathrm{~min}$ for $120 \mathrm{~min}$ after $\mathrm{T}_{0}\left(\mathrm{~T}_{30}, \mathrm{~T}_{60}, \mathrm{~T}_{90}\right.$ and $\left.\mathrm{T}_{120}\right)$ and once at the $8 \mathrm{~h}$ point after $\mathrm{T}_{0}\left(\mathrm{~T}_{8 \mathrm{~h}}\right)$. Blood gases were measured at $\mathrm{T}_{0}$ and $\mathrm{T}_{120}$. CO was detected using color Doppler echocardiography [Aloka-SSD 5000-SV, Japan, or LOGIQ BOOK portable ultrasound scanners, GE, USA], and the $\mathrm{CO}$ parameters were calculated according to the recommendations of the American Society of Echocardiography $[40,41]$.

Random grouping of cases and registration of parameters were operated by professional statisticians at the hospitals rather than by physicians. $\mathrm{CO}$ was measured by a professional echocardiographic doctor.

\section{Statistical analysis}

Data were analyzed using SPSS for Windows, v13.0 (SPSS Inc, Chicago, IL, USA). A two-way ANOVA, with one of 
Table I: Clinical features, baseline demographic and physiological variables on admission in the three groups

\begin{tabular}{|c|c|c|c|}
\hline & Ns group & Hs group & Sb group \\
\hline Age (means $\pm S D)$ & $44.19 \pm 22.51$ & $49.17 \pm 21.39$ & $32.59 \pm 19.08 \dagger$ \\
\hline median (min-max) & $39(5-79)$ & $50(5-83)$ & $31(15-76)$ \\
\hline Male/Female & $20 / 12$ & $19 / 11$ & $15 / 17$ \\
\hline APACHEA II score & $18.69 \pm 3.69$ & $19.97 \pm 4.23$ & $18.00 \pm 3.82$ \\
\hline Predictive mortality by APACHE II & $42.94 \% \pm 13.30 \%$ & $49.13 \% \pm 18.22 \%$ & $40.38 \% \pm 15.48 \%$ \\
\hline SAPS II score & $29.31 \pm 8.05$ & $33.59 \pm 9.76$ & $27.03 \pm 9.52$ \\
\hline Predictive mortality rate for SAPS II & $12.16 \% \pm 9.58 \%$ & $17.80 \% \pm 12.54 \%$ & $10.69 \% \pm 10.59 \%$ \\
\hline SOFA & $8.97 \pm 1.82$ & $9.17 \pm 2.46$ & $8.44 \pm 2.00$ \\
\hline Observed mortality & $5 / 32(15.63 \%)$ & $5 / 30(16.67 \%)$ & $5 / 32(15.63 \%)$ \\
\hline \multicolumn{4}{|l|}{ Diagnosis } \\
\hline Acute enteritis & 1 & & 1 \\
\hline Acute nonlymphoblastic leukemia & 11 & 13 & 7 \\
\hline Agranulocytosis & & 1 & \\
\hline Aplastic anemia & & 1 & 2 \\
\hline Bacillary dysentery & 5 & 3 & 3 \\
\hline Bronchopneumonia & I & & \\
\hline Cholecystitis & 2 & 3 & 2 \\
\hline Chronic myeloid leukemia & 3 & I & \\
\hline Fulminent $\mathrm{N}$ meningitis & & I & \\
\hline Kidney cancer & & I & 1 \\
\hline Multiple trauma & 2 & i & 2 \\
\hline Peritonitis & & & 2 \\
\hline Pneumonia & 3 & 2 & 7 \\
\hline Osteomyelitis & I & I & \\
\hline Septicemia & 2 & 3 & 6 \\
\hline Urinary tract infection & I & & 1 \\
\hline \multicolumn{4}{|l|}{ Microbiology } \\
\hline Acinetobacter baumannii & 1 & & \\
\hline Candida albicans & 4 & 2 & 2 \\
\hline Escherichia aerogenes & I & & \\
\hline Escherichia cloacae & I & 4 & \\
\hline Escherichia coli & 5 & 9 & 9 \\
\hline Gram-negative bacilli & 4 & 1 & 2 \\
\hline Gram-positive bacilli & 2 & 2 & 6 \\
\hline Pseudomonas aeruginosa & & 2 & I \\
\hline Mucor & & 2 & \\
\hline Myososis & & I & \\
\hline N. meningococcus & & i & \\
\hline Shigella boydii & 3 & 1 & 1 \\
\hline Shigella dysenteriae & 3 & 2 & 3 \\
\hline Staphylococcus & I & & 3 \\
\hline Streptococcus viridans & I & 1 & \\
\hline Negative & 6 & 2 & 5 \\
\hline
\end{tabular}

Values are expressed as mean \pm standard deviation. Compared with the Ns group, ${ }^{\dagger} \mathrm{p}<0.05$. APACHE, Acute Physiology and Chronic Health Evaluation score; SAPS, Simplified Acute Physiology Score; SOFA, Sequential Organ Assessment.

the ways being repeated measures, was performed first. Then a statistician tested for differences between the groups directly and for differences within a group. All physiological values are given as means $\pm \mathrm{SD}$, but age is presented as mean \pm SD and median (minimum-maximum). Significance was defined as $p<0.05$.

\section{Results \\ Patient outcomes}

The demographic data are presented in Table 1. Before solution resuscitation was started there were no significant differences among the three groups in severity scores (APACHE II, SAPSII and SOFA). When the expected mortalities in the Ns group were compared with those in the Hs or the Sb group by the APACHE II and SAPS II scores, no significant differences were found (Table 1). Intervention was completed in all 94 patients in $120 \mathrm{~min}$, and the 
follow-up was completed in $8 \mathrm{~h}$. Five patients in the Ns group died on the $6^{\text {th }}, 10^{\text {th }}, 18^{\text {th }}, 20^{\text {th }}$ and $25^{\text {th }}$ days following intervention; 5 in the Hs group died on the $7^{\text {th }}, 9^{\text {th }}$, $15^{\text {th }}, 20^{\text {th }}$ and $25^{\text {th }}$ days; and 5 in the Sb group died on the $6^{\text {th }}, 10^{\text {th }}, 15^{\text {th }}, 19^{\text {th }}$ and $25^{\text {th }}$ days. There were no significant differences in mortality rates between the Ns, Hs and Sb groups.

\section{Cardiac output and blood pressure}

On admission, all the patients had abnormal temperature, abnormal white blood cell count, hyperpnea, tachycardia, decreased CO and hypotension.

Echocardiograms were recorded by the Teichholz method from the left parasternal window, and the parameters of cardiac function such as $\mathrm{CO}$ were read directly. At $\mathrm{T}_{0}$, the $\mathrm{CO}$ was $3.17 \pm 0.79 \mathrm{l} / \mathrm{min}$ in the Ns group, $3.37 \pm 0.99 \mathrm{l} /$ min in the Hs group and $3.34 \pm 0.65 \mathrm{l} / \mathrm{min}$ in the $\mathrm{Sb}$ group. $\mathrm{CO}$ was compared at serial time points after fluid resuscitation with that at $\mathrm{T}_{0}$ in the same group: it increased significantly at $\mathrm{T}_{120}$ in the Ns group, at $\mathrm{T}_{8 \mathrm{~h}}$ in the Hs group and at $\mathrm{T}_{60}$ in the $\mathrm{Sb}$ group (Fig. 1). CO improved earlier in the $\mathrm{Sb}$ group than in the Ns or Hs groups. However, there were no differences in $\mathrm{CO}$ among the three groups at the same time points.

In all three groups, MAP at $\mathrm{T}_{0}$ was lower than $70 \mathrm{~mm} \mathrm{Hg}$ : $61.21 \pm 9.69 \mathrm{~mm} \mathrm{Hg}$ in the Ns group, $62.55 \pm 10.95 \mathrm{~mm}$ $\mathrm{Hg}$ in the $\mathrm{Hs}$ group and $59.38 \pm 9.79 \mathrm{~mm} \mathrm{Hg}$ in the $\mathrm{Sb}$ group. Normal saline treatment resulted in a marked increase of MAP at $\mathrm{T}_{60}, 3.5 \%$ sodium chloride at $\mathrm{T}_{8 \mathrm{~h}}$ and $5 \%$ sodium bicarbonate at $\mathrm{T}_{30}$. MAP improved earlier in the $\mathrm{Sb}$ group than in the Ns and Hs groups. However, there were no differences in MAP among the three groups at the same time points (Fig. 2).

On admission, the patients in all three groups suffered from hyperpnea and tachycardia. Fluid resuscitation did

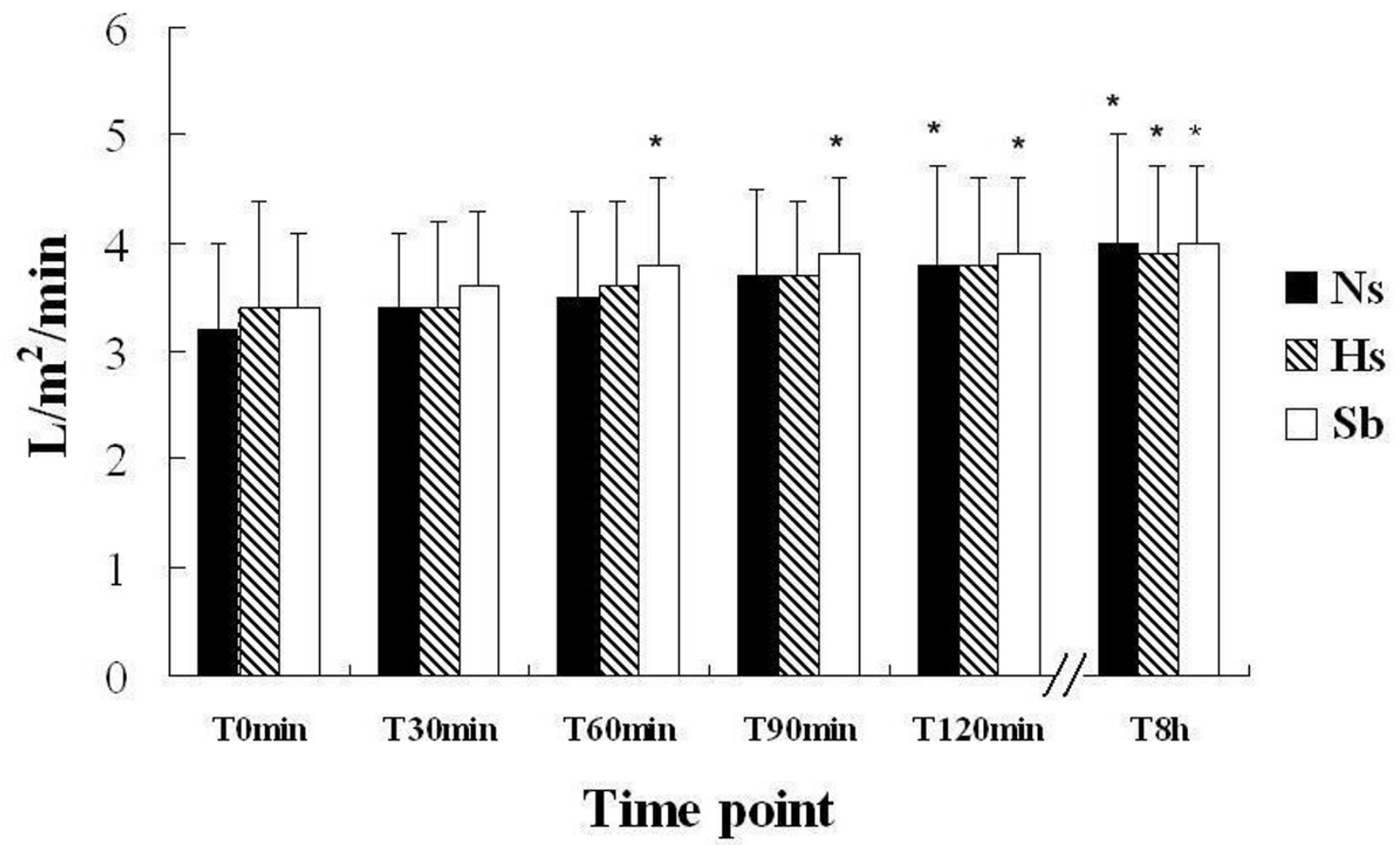

Figure I

Effects of fluid resuscitation on $\mathrm{CO}$ in the three groups. The trial program and case grouping were carried out according to the design indicated in Methods. CO was measured by Doppler echocardiography. There were no differences in $\mathrm{CO}$ among the three groups at all the six time points. Comparing the $\mathrm{CO}$ variables in the same group, $\mathrm{CO}$ at $\mathrm{T}_{120}$ and $\mathrm{T}_{8 \mathrm{~h}}$ was significantly higher than at $\mathrm{T}_{0}$ in the Ns group; the parameter at $\mathrm{T}_{8 \mathrm{~h}}$ was higher than at $\mathrm{T}_{0}$ in the $\mathrm{Hs}_{\mathrm{s}}$ group; and $\mathrm{CO}_{\text {at }} \mathrm{T}_{60}$, $\mathrm{T}_{90}, \mathrm{~T}_{120}$ and $\mathrm{T}_{8 \mathrm{~h}}$ were higher than that at $\mathrm{T}_{0}$ in the Sb group $\left({ }^{*} \mathrm{p}<0.05\right)$. CO improved earlier in the Sb group than in the $\mathrm{Ns}$ and $\mathrm{Hs}$ groups. 


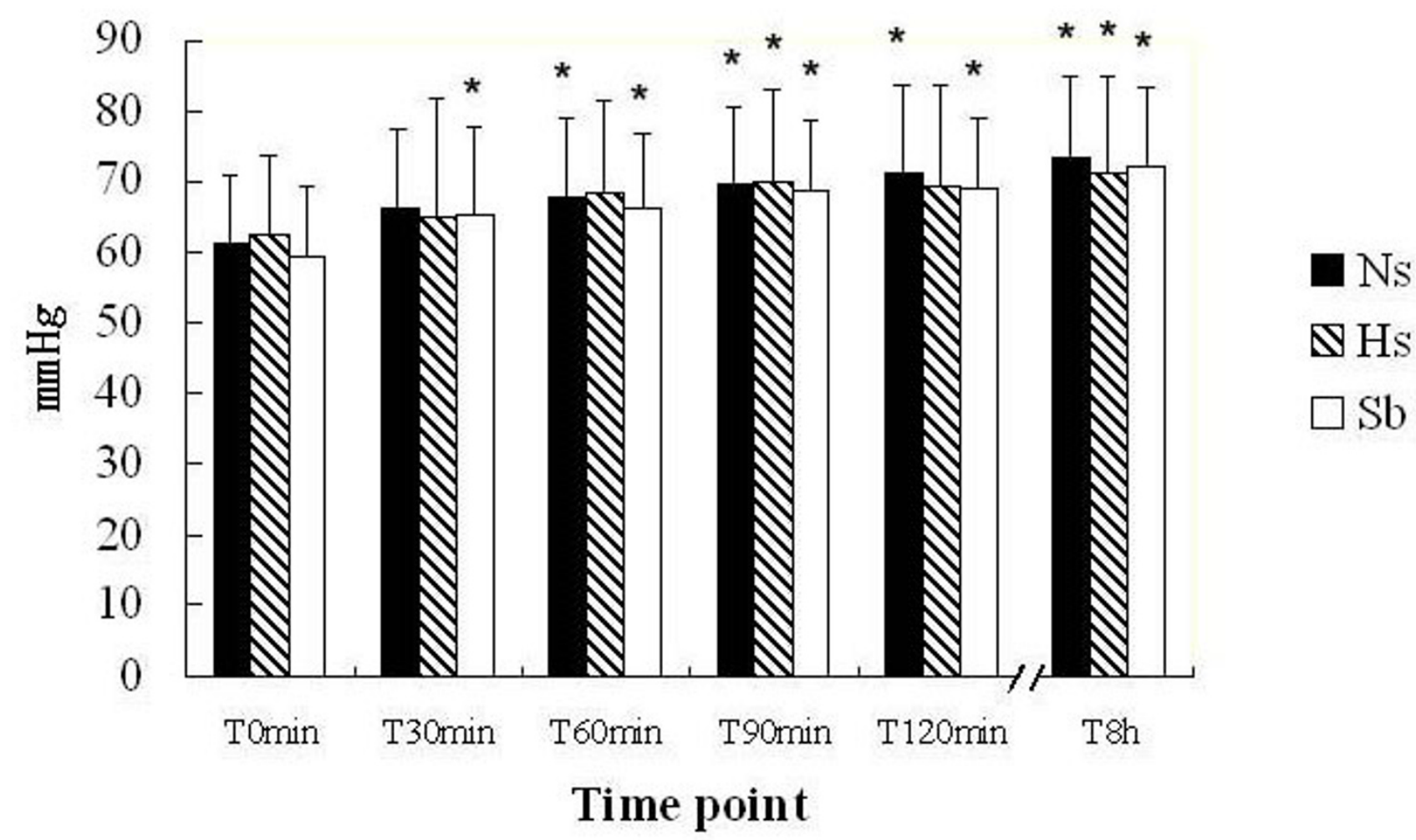

Figure 2

Effects of fluid resuscitation on MAP in the three groups. MAP in all patients was registered by professional statisticians in the hospitals. There were no differences in MAP among the three groups at all the six time points. Comparing MAP in the same group, MAP at $T_{60}, T_{90}, T_{120}$ and $T_{8 h}$ was significantly higher than that at $T_{0}$ in the Ns group; the parameter at $T_{90}$, $T_{120}$ and $\mathrm{T}_{8 \mathrm{~h}}$ was higher than at $\mathrm{T}_{0}$ in the Hs group; and MAP at $\mathrm{T}_{30}, \mathrm{~T}_{60}, \mathrm{~T}_{90}, \mathrm{~T}_{120}$ and $\mathrm{T}_{8 \mathrm{~h}}$ were higher than that at $\mathrm{T}_{0}$ in the Sb group (*P $<0.05)$. MAP increased earlier in the Sb group than in the $\mathrm{Ns}$ and $\mathrm{Hs}$ groups.

not alter the heart rates or respiratory rates after $120 \mathrm{~min}$ in any of the three groups, but caused a decrease of heart and respiratory rates in the Sb group and a decrease of heart rate in the Ns group at $\mathrm{T}_{8 \mathrm{~h}}$ (Figs. 3 and 4 ).

\section{Acid-basic balance and electrolytes}

The blood $\mathrm{pH}$, lactic acid and $\left[\mathrm{HCO}_{3}\right]^{-}$values in the three groups were not altered during the $120 \mathrm{~min}$ following treatment. The base excess (BE) values in the Ns and Hs groups were not changed at $\mathrm{T}_{120}$ whereas those of the $\mathrm{Sb}$ group were increased. The $\mathrm{BE}$ values of the $\mathrm{Sb}$ group at $\mathrm{T}_{120}$ were higher than those of the Ns group. Sodium bicarbonate improved the BE values (Table 2).

Fluid resuscitation, whether with normal saline, 3.5\% sodium chloride or $5 \%$ sodium bicarbonate, did not alter the $\mathrm{Na}^{+}, \mathrm{K}^{+}, \mathrm{Ca}^{2+}$ or $\mathrm{Cl}^{-}$levels in any of the three groups. However, $\mathrm{K}^{+}$in the $\mathrm{Sb}$ group was lower than that in the Ns group at $\mathrm{T}_{120}$. Blood urea nitrogen was not altered in any group.

\section{Discussion}

The major findings of the present study were: that in patients with severe sepsis, there were no differences in $\mathrm{CO}, \mathrm{MAP}$, heart rate or respiratory rate between the three groups during the $120 \mathrm{~min}$ trial or the $8 \mathrm{~h}$ follow-up; that there were no significant differences between the Ns group and the Hs or $\mathrm{Sb}$ groups in observed mortality rate at 28 days; and that sodium bicarbonate improved MAP and $\mathrm{CO}$ more rapidly than normal saline or hypertonic sodium chloride. However, the benefits of sodium bicarbonate were limited.

Previous studies have demonstrated that initial crystalloid volume loading is valuable in achieving hemodynamic stability [1-4]. Consistent with previous studies, we observed the benefits of normal saline during the $120 \mathrm{~min}$ trial, namely MAP rising at $\mathrm{T}_{60}$ and $\mathrm{CO}$ increasing at $\mathrm{T}_{120}$. All 94 patients were treated with crystalloid fluids, but no vasopressors, inotropic agents, colloids or mechanical ventilation were administered within the initial two hours, so the improvement of patient status was certainly 


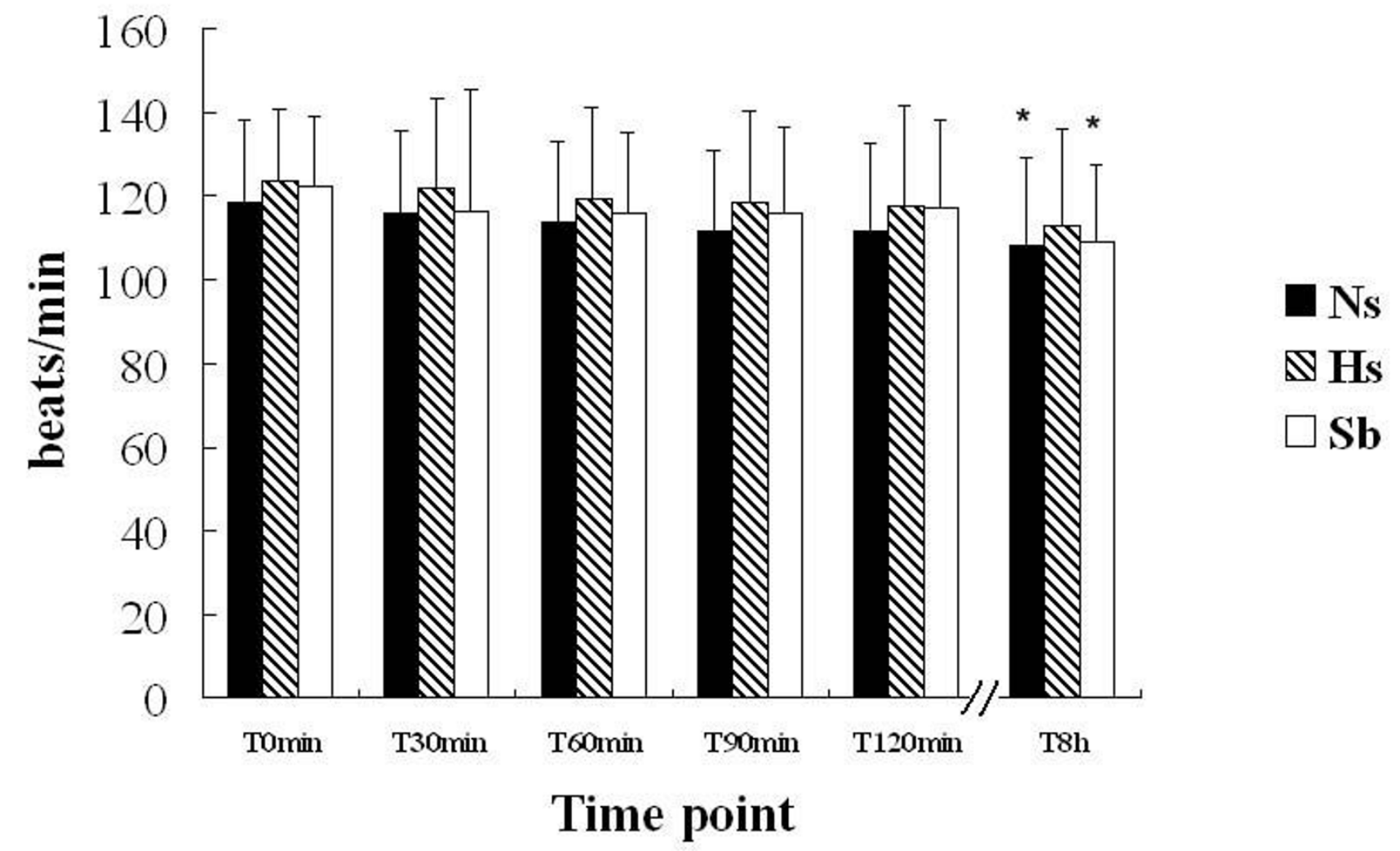

Figure 3

Effects of fluid resuscitation on heart rate in the three groups. Heart rate in all cases was recorded by statisticians. There were no differences in heart rate among the groups during the $120 \mathrm{~min}$ trial or the $8 \mathrm{~h}$ follow-up. Comparing heart rate in the same group, the heart rate at $T_{8 h}$ was lower than that at $T_{0}$ in the Ns and Sb groups (*p $\left.<0.05\right)$, but no change of heart rate appeared in the Hs group. Resuscitation by fluids did not change heart rate in patients during the 120 min trial.

caused by normal saline perfusion. This indicates that normal saline can be used for initial volume loading in severe sepsis.

Small volume hypertonic saline is as effective as large-volume isotonic crystalloids in expanding plasma volume and enhancing cardiac output in hemorrhagic shock in animals [42]. Hypertonic saline increases microcirculatory perfusion, presumably by selective arteriolar vasodilatation and by decreasing the swelling of red blood cells and the endothelium [43]. Recent studies demonstrate that hypertonic saline resuscitation reduces the inflammatory reaction in severe sepsis and septic shock [44-47]. In experimental sepsis, the hemodynamic responses to hypertonic saline solution are conflicting: improvement in rats, dogs and pigs [1], no alteration in horses or macaques $[13,48]$, and worsening cardiac contractibility in rabbits [12]. In clinical trials, hypertonic saline with or without a colloidal solution modifies the hemodynamics of patients with sepsis or septic shock. Hypertonic saline/ dextran solution improves cardiovascular performance
[5], and hypertonic saline/hydroxyethyl starch results in increased cardiac output and pulmonary capillary wedge pressure, but no alteration of $\mathrm{O}_{2}$ metabolism [6]. Muller reports that $250 \mathrm{ml} 7.5 \%$ hypertonic saline without colloid transiently increases the cardiac index and pulmonary capillary wedge pressure in patients with severe sepsis during a $120 \mathrm{~min}$ trial [7]. There is a difference in hemodynamic effects between hypertonic saline with colloid and hypertonic saline without colloid. We speculate that the colloid prolongs the effectiveness of the hypertonic solution.

In the present study, $3.5 \%$ saline at $5 \mathrm{ml} / \mathrm{kg}$ did not alter the CO of patients during the $120 \mathrm{~min}$ trial. The effect of $3.5 \%$ sodium chloride was very little different from that of $7.5 \%$ sodium chloride in Muller's trial. This might be attributable to the difference in osmotic pressure between these two fluids, $1197 \mathrm{mOsm} / \mathrm{l}$ in $3.5 \%$ sodium chloride and $2565 \mathrm{mOsm} / \mathrm{l}$ in $7.5 \%$ sodium chloride solution. 


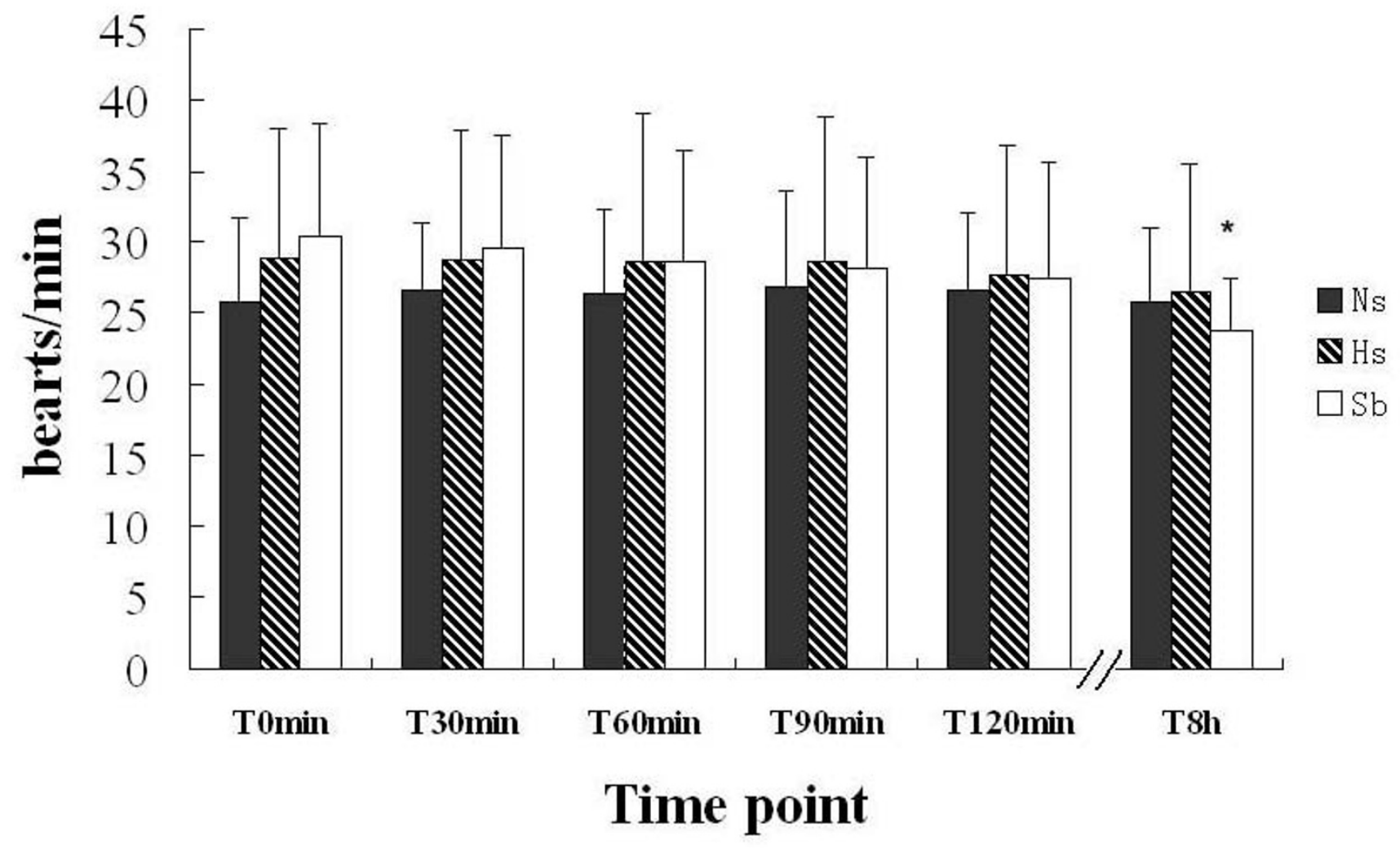

Figure 4

Effects of fluid resuscitation on respiratory rate in the three groups. There were no differences in respiratory rate among the groups during the $120 \mathrm{~min}$ trial or the $8 \mathrm{~h}$ follow-up. Comparing respiratory rates in the same group, the respiratory rate at T8h was lower than that at T0 in the Sb group $\left(*_{p}<0.05\right)$ only; no change of respiratory rate appeared in the Ns or Hs groups. Resuscitation by fluids did not change the respiratory rate of patients during the I 20 min trial.

Sodium bicarbonate was applied empirically by clinicians before the 1990s in the initial fluid resuscitation of septic shock [15-18]. However, experimental studies of the effect of sodium bicarbonate conflicted. Bollaert et al. demonstrated that sodium bicarbonate treatment does not reduce metabolic cellular injury in skeletal muscle but further reduces MAP in rat models with endotoxic shock [27]. In our study in rabbits [12], 5\% sodium bicarbonate induced a decrease in MAP and cardiac contractility, and eventually resulted in the death of the animals. Gossett reports that in ponies with endotoxemia, hypertonic sodium bicarbonate infusion causes blood volume expansion, increases blood bicarbonate concentration and lactate concentration, results in hypokalemia, hypernatremia and hyperosmolality, but does not normalize blood $\mathrm{pH}$ [26]. In contrast, our recent study reports that in macaques with early-phase endotoxic shock, normal saline resuscitation further decreases the MAP, cardiac index, left ventricular work index and right ventricular work index, whereas macaques given $5 \%$ sodium bicarbonate show moderate increases of cardiac index, left ven- tricular work index and right ventricular work index. Five percent sodium bicarbonate improves cardiac function in primate models [13]. The above findings indicate that there are differences in the effect of sodium bicarbonate on hemodynamics between primates and non-primates.

The effects of sodium bicarbonate resuscitation in patients with severe sepsis and early-phase septic shock are consistent with those in macaques [13]. In the present study, sodium bicarbonate improved MAP and CO more quickly than normal saline. Sodium bicarbonate manifested a limited beneficial cardiovascular efficiency during the early phase of fluid resuscitation in the patients. Comparing the data from the Hs group with those from the $\mathrm{Sb}$ group, a beneficial effect of $5 \%$ sodium bicarbonate was that it improved CO and MAP more quickly than 3.5\% saline.

In clinical investigations, there are minor differences in the effect of sodium bicarbonate. Mathieu et al. [49] report that administration of sodium bicarbonate does 
Table 2: Changes of acid-base balance and electrolytes over I 20 $\min$ in the three groups

\begin{tabular}{|c|c|c|c|}
\hline & Ns group & Hs group & Sb group \\
\hline \multicolumn{4}{|l|}{$\mathrm{pH}$} \\
\hline$T_{0}$ & $7.33 \pm 0.16$ & $7.40 \pm 0.11$ & $7.38 \pm 0.12$ \\
\hline $\begin{array}{l}T_{120} \\
B E-B\end{array}$ & $7.34 \pm 0.12$ & $7.36 \pm 0.16$ & $7.44 \pm 0.06$ \\
\hline $\mathrm{T}_{0}$ & $-7.21 \pm 6.27$ & $-5.26 \pm 6.57$ & $-4.10 \pm 7.06$ \\
\hline $\begin{array}{l}\mathrm{T}_{120} \\
{\left[\mathrm{HCO}_{3}\right]^{-}(\mathrm{mmol} / \mathrm{l})}\end{array}$ & $-5.62 \pm 6.83$ & $-5.83 \pm 8.76$ & $1.64 \pm 4.23 * \dagger$ \\
\hline $\mathrm{T}_{0}$ & $18.43 \pm 4.87$ & $|7.76 \pm 6.5|$ & $20.84 \pm 5.74$ \\
\hline $\begin{array}{l}\mathrm{T}_{120} \\
\text { Lactic acid }(\mathrm{mmol} / \mathrm{l})\end{array}$ & $19.77 \pm 6.94$ & $16.43 \pm 7.84$ & $24.27 \pm 6.08$ \\
\hline $\mathrm{T}_{0}$ & $8.15 \pm 8.05$ & $3.35 \pm 0.21$ & $4.30 \pm 1.98$ \\
\hline $\begin{array}{l}\mathrm{T}_{120} \\
\mathrm{Na}^{+}(\mathrm{mmol} / \mathrm{l})\end{array}$ & $1.37 \pm 0.11$ & $3.15 \pm 0.07$ & $3.48 \pm 1.70$ \\
\hline $\mathrm{T}_{0}$ & $|35.9| \pm 7.21$ & $135.86 \pm 9.52$ & $135.15 \pm 7.00$ \\
\hline $\begin{array}{l}\mathrm{T}_{120} \\
\mathrm{~K}^{+}(\mathrm{mmol} / \mathrm{l})\end{array}$ & $136.70 \pm 5.90$ & $135.62 \pm 10.19$ & $138.57 \pm 6.89$ \\
\hline $\mathrm{T}_{0 \min }$ & $3.93 \pm 0.84$ & $3.78 \pm 0.71$ & $4.02 \pm 0.47$ \\
\hline $\begin{array}{l}\mathrm{T}_{120 \min } \\
\mathrm{Ca}^{2+}(\mathrm{mmol} / \mathrm{L})\end{array}$ & $4.11 \pm 0.71$ & $3.83 \pm 0.56$ & $3.77 \pm 0.59 \dagger$ \\
\hline $\mathrm{T}_{0}$ & $2.12 \pm 0.28$ & $1.96 \pm 0.50$ & $2.35 \pm 0.43$ \\
\hline $\begin{array}{l}\mathrm{T}_{120} \\
\mathrm{Cl}^{-}(\mathrm{mmol} / \mathrm{l})\end{array}$ & $2.17 \pm 0.33$ & $2.05 \pm 0.36$ & $2.28 \pm 0.53$ \\
\hline $\mathrm{T}_{0}$ & $94.49 \pm 18.58$ & $97.90 \pm 10.89$ & $99.02 \pm 4.40$ \\
\hline $\begin{array}{l}T_{120} \\
\text { BUN (mmol/l) }\end{array}$ & $98.41 \pm 5.18$ & $97.78 \pm 5.10$ & $98.93 \pm 3.39$ \\
\hline $\mathrm{T}_{0}$ & $9.75 \pm 8.48$ & $7.53 \pm 4.85$ & $7.99 \pm 7.33$ \\
\hline$T_{120}$ & $9.00 \pm 8.16$ & $10.09 \pm 6.25$ & $7.74 \pm 7.96$ \\
\hline
\end{tabular}

Values are expressed as mean \pm standard deviation. Compared with $\mathrm{T}_{0 \text { min }}$ in the same group, $* p<0.05$. Compared with Ns group at the same time point, $\dagger p<0.05$.

not improve hemodynamic variables in patients with metabolic acidosis, nor does it worsen tissue oxygenation. Cooper [50] found that the MAP responses to sodium bicarbonate and sodium chloride are the same in patients with metabolic acidosis. These data have more than $90 \%$ power for detecting a $0.5 \mathrm{l} / \mathrm{min}$ difference in mean $\mathrm{CO}$ after administration of sodium bicarbonate or sodium chloride. In lactic acidosis accompanied by refractory shock, patients receiving sodium bicarbonate show improvements in neither acid-base balance nor hemodynamics [51]. In the present study, MAP and CO improved more quickly in patients treated with sodium bicarbonate than in patients treated with normal saline or hypertonic sodium chloride. The conflict between our data and those of other authors may be a result of different physiological status before fluid resuscitation: metabolic acidosis in Mathieu's papers, moderate hypotension in the present study and refractory shock in Stacpoole's investigation [51].

Primates, including humans and macaques, appear to tolerate hyperosmotic solutions and acid-alkali balance as potential treatment for septic shock. The severe side- effects of hyperosmotic sodium bicarbonate perfusion in non-primates are hyperosmolarity and hypernatraemia, raised lactic acid and $\mathrm{pH}$, and altered $\mathrm{PaCO}_{2}$ and $\left[\mathrm{HCO}_{3}\right]^{-}$ [52-55]. However, in macaques with early-phase endotoxic shock and presenting neither acidosis nor lacticemia, injection of $5 \mathrm{ml} / \mathrm{kg} 5 \%$ sodium bicarbonate does not result in increased osmolarity or plasma sodium, or in altered $\mathrm{pH},\left[\mathrm{HCO}_{3}\right]^{-}$or lactic acid $60 \mathrm{~min}$ after fluid resuscitation [13]. Consistent with the investigation of macaques, patients in the present study with normal $\mathrm{pH}$ $(\mathrm{pH}=7.38)$ and receiving sodium bicarbonate showed increased $\mathrm{BE}$, decreased $\mathrm{K}^{+}$but no alteration of $\mathrm{pH}$, $\left[\mathrm{HCO}_{3}\right]^{-}$, lactic acid, $\mathrm{Na}^{+}, \mathrm{Ca}^{2+}$ or $\mathrm{Cl}^{-}$during the $120 \mathrm{~min}$ trials. The data in macaques and patients indicate that a bolus injection of $5 \mathrm{ml} / \mathrm{kg}$ sodium bicarbonate did not affect the acid-basic balance or electrolytes in primates. Sodium bicarbonate might have the same benefits in humans and macaques because primates share similar physiological functions, namely better tolerance to hypertonic solution, volume loading and acid-basic balance $[13,14,18]$. Therefore, we consider that a bolus injection of $5 \mathrm{ml} / \mathrm{kg}$ sodium bicarbonate in the initial fluid resuscitation of severe sepsis is safe - at least it does not worsen the physiological signs of the patients - and this treatment can still be used in cases of severe sepsis and early phase septic shock in humans, but should be deployed with care.

The benefits of the three crystalloid solutions were similar during the $120 \mathrm{~min}$ trial and the $8 \mathrm{~h}$ follow-up. The MAP and CO during the initial $120 \mathrm{~min}$ did not differ among the three groups, and their MAPs had recovered at $\mathrm{T}_{8 \mathrm{~h}}$ (>70 mmHg). Also, there was no difference among the three groups in observed mortality rates. In addition, fluid resuscitation, whether with normal saline, 3.5\% sodium chloride or $5 \%$ sodium bicarbonate, did not alter the heart or respiratory rate in any group during the subsequent $120 \mathrm{~min}$. We consider that all the three fluids may be used for initial volume loading in severe sepsis and early-phase septic shock.

Assessments of the severity of organ dysfunction and of physiological status are critical tools for conducting clinical trials, especially sepsis trials. The APACHEA II score, SAPS II score, SOFA and the expected mortality rates were used to judge the severity of patients in previous studies [56]. In the present study, there were no differences in APACHEA II score, SAPS II score, SOFA or the expected mortality rates for APACHE II or SAPS II scores on admission among the three groups, but the age of the Sb group was lower than that of the Ns and Hs groups. Thus, similar pathophysiological scores appeared in the three groups on admission despite this age difference. In general, the populations of the three groups were balanced. 
Clinical trials emphasize ethical principles. To ensure a favorable risk-benefit profile, all treatment regimens must provide efficacy and limited risk, with minimal or no emergence of organ injury. In the present study, a regimen was utilized that included a bolus of $5 \mathrm{ml} / \mathrm{kg}$ of various solutions at $\mathrm{T}_{0}$, no vasoactive agents or colloid before $\mathrm{T}_{120^{\prime}}$ and permitted use of vasoactive agents or colloid for hemodynamic stability after $T_{120}$. This design was chosen for the following reasons. First, crystalloid solutions are effective as immediate perfusions in initial volume replacement, but these effects have a short (2-3 h) period of action [34]. In macaque models, the experiments lasted for $60 \mathrm{~min}$, during which time sodium bicarbonate improved myocardial performance and hemodynamics [13]. In the paper by Chrusch and coworkers on the organ metabolism of lactate in dogs with sepsis, the experiment was limited to less than 75 min following fluid resuscitation [57]. Therefore, $120 \mathrm{~min}$ duration is suitable for the study of resuscitation by crystalloid solutions. Second, in order to investigate the effect of crystalloid solutions on hemodynamics, vasoactive agents or colloid must not be administered concurrently with this solution resuscitation because vasoactive agents may influence cardiovascular function intensively. But in clinical practice, if fluid resuscitation does not raise blood pressure and restore hemodynamic stability, vasoactive agents should be used to improve the patient's physiological status [39]. Finally, only patients with early-phase septic shock were included in the investigation. The trial included patients with earlyphase septic shock because they were tolerant of treatment with single crystalloid solutions within $120 \mathrm{~min}$. The trial excluded patients with final-phase septic shock, because they might require vasoactive agents, colloid or other treatment within $2 \mathrm{~h}$ of initial intervention in order to survive; these patients were therefore not suitable for observation.

\section{There are limitations to this study.}

First, although the patients were randomly assigned to three groups, the groups were highly heterogeneous in e.g. age and lactic acid level [see Tables 1 \&2]. The imbalance between groups could not be avoided in a trial that was conducted over a long period (52 months from Jun 01, 2001 to Oct 31, 2005). Fortunately, there were no significant differences in severity scores between the three groups. Those data indicated that the population was balanced between the three groups. Second, we did not use a pulmonary artery catheter to measure cardiac output, mean central venous pressure or pulmonary arterial wedge pressure, because pulmonary artery catheterization, an invasive technique, is not commonly accepted by patients with early phase septic shock. Therefore, in the present protocol, CO was measured by color Doppler echocardiography. Unfortunately, this technique only analyzed CO; it did not yield essential information about preload assessment (i.e. pulmonary arterial wedge pressure, ventricular working index), oxygen consumption or oxygen delivery. Finally, many leukemic cases were enrolled because those patients were prone to infection, and hypotension was easily detected in inpatients.

\section{Conclusion}

In summary, we demonstrated that all three crystalloid solutions - normal saline, 3.5\% hypertonic sodium chloride and 5\% sodium bicarbonate - may be used for initial volume loading in patients with severe sepsis and hypotension. Sodium bicarbonate improved MAP and CO earlier than normal saline or hypertonic sodium chloride, which indicates that sodium bicarbonate has a limited benefit for treating severe sepsis in humans.

\section{Competing interests}

The author(s) declare that they have no competing interests.

\section{Authors' contributions}

ZXF participated in the design and management of the investigation. YFL conducted the study and performed the clinical trial at the First People's Hospital of Huai'an City; XQZ conducted the study and performed the clinical trial at the People's hospital of Gaochun County; ZZ conducted the study and performed the clinical trial in the emergency department of the First Hospital of Nanjing; and JSZ conducted the study and performed the clinical trial in the emergency department of the Jiangsu Province Hospital. HMX, WPS and LS performed the statistical analysis and literature search. GPX analyzed the Doppler echocardiography. GQY presented the original idea for the article, and planned and wrote the paper. All authors read and approved the final manuscript.

\section{Acknowledgements}

We are grateful for useful comments on the manuscript by Prof Fei Rong Gu of Nanjing Agricultural University. This research program is supported by the Health Office of the Jiangsu Provincial Govermment TS 9904.

\section{References}

I. Oliveira RP, Velasco I, Soriano F, Friedman G: Hypertonic saline resuscitation in sepsis. Crit Care 2002, 6:4I8-423.

2. Healey MA, Davis RE, Liu FC, Loomis WH, Hoyt DB: Lactated Ringer's is superior to normal saline in a model of massive hemorrhage and resuscitation. J Trauma 1998, 45:894-899.

3. Soucy DM, Rude M, Hsia WC, Hagedorn FN, Illner H, Shires GT: The effects of varying fluid volume and rate of resuscitation during uncontrolled hemorrhage. J Trauma 1999, 46:209-2I5.

4. Vincent JL, Gerlach H: Fluid resuscitation in severe sepsis and septic shock: an evidence-based review. Crit Care Med 2004, 32( I I Suppl):S45 I-454.

5. Oliveira RP, Weingartner R, Ribas EO, Moraes RS, Friedman G: Acute hemodynamic effects of a hypertonic saline/dextran solution in stable patients with severe sepsis. Intensive Care Med 2002, 28: |574-|58|.

6. Hannemann L, Reinhart K, Korell R, Spies C, Bredle DL: Hypertonic saline in stabilized hyperdynamic sepsis. Shock 1996, 5:130-134. 
7. Muller L, Lefrant JY, Jaber S, Louart G, Mahamat A, Ripart J, de La Coussaye JE, Eledjam JJ: Short term effects of hypertonic saline during severe sepsis and septic shock. Ann Fr Anesth Reanim 2004, 23:575-580.

8. Garrido AP, Cruz Junior RJ, Poli de Figueiredo LF, Rocha e Silva M: Small volume of hypertonic saline as the initial fluid replacement in experimental hypodynamic sepsis. Crit Care 2006 , I0:R62.

9. Ing RD, Nazeeri MN, Zeldes S, Dulchavsky SA, Diebel LN: Hypertonic saline/dextran improves septic myocardial performance. Am Surg 1994, 60:505-507.

10. Somell A, Sollevi A, Suneson A, Riddez L, Hjelmavist H: Beneficial effects of hypertonic saline/dextran on early survival in porcine endotoxin shock. Acta Anaesthesiol Scand 2005, 49: I I 24- I I 34.

II. Maciel F, Mook M, Zhang H, Vincent JL: Comparison of hypertonic with isotonic saline hydroxyethyl starch solution on oxygen extraction capabilities during endotoxic shock. Shock 1998, 9:33-39.

12. Zhang YS, Liu QS, Yin GQ, Zhong B: Effect of $5 \%$ sodium bicarbonate perfusion at different dose on cardiac function in rabbits with infective shock by Meningcoccus. J Nanjing Railway Med College 1999, I 8:|48-I5|

13. Yin GQ, Qiu HB, Du KH, Tang JQ, Lu CP, Fang ZX: Endotoxic shock model with fluid resuscitation in Macaca mulatta. Lab Anim 2005, 39:269-279.

14. Yin GQ, Ji XH, Gu FR, Lu CP, Fang ZX, Zhao W, Chen Y, Shen L, Tang JQ: Effect of fluid resuscitation on ryanodine receptor in macaques with endotoxic shock. Resuscitation 2006, 70: | 45- 152.

15. Ellis W, Dodson M: Severe septic shock treated successfully with sodium bicarbonate. J Bone Joint Surg Br 1964, 46:746-747.

16. Vain NE, Mazlumian JR, Swarner OW, Cha CC: Role of exchange transfusion in the treatment of severe septicemia. Pediatrics 1980, 66:693-697.

17. Brandao MB, Lopes CE, Morcillo AM, Baracat EC: Risk factors of death in children with diarrhea and shock admitted to the intensive care unit. Rev Assoc Med Bras 2005, 5 I:237-240.

18. Yin GQ, Qiu HB, Du KH, Tang JQ, Lu CP, Fang ZX: Author reply: Endotoxic shock model with fluid resuscitation in Macaca mulatta. Lab Anim 2006, 40:104-106.

19. Warner A, Vaziri ND: Treatment of lactic acidosis. South Med |981, 74:84|-847.

20. von Planta I, Weil MH, von Planta M, Gazmuri RJ, Duggal C: Hypercarbic acidosis reduces cardiac resuscitability. Crit Care Med 1991, 19:1 I77-II82.

21. Kerber RE, Pandian NG, Hoyt R, Jensen SR, Koyanagi S, Grayzel J Kieso R: Effect of ischemia, hypertrophy, hypoxia, acidosis, and alkalosis on canine defibrillation. Am J Physiol 1983 , 244:H825-83।

22. Bonventre JV, Cheung JY: Effects of metabolic acidosis on viability of cells exposed to anoxia. Am J Physiol 1985, 249: CI49-I59.

23. Gores GJ, Nieminen AL, Wray BE, Herman B, Lemasters JJ: Intracellular pH during "chemical hypoxia" in cultured rat hepatocytes. Protection by intracellular acidosis against the onset of cell death. J Clin Invest 1989, 83:386-396.

24. Preckel B, Schlack W, Obal D, Barthel H, Ebel D, Grunert S, Thamer $\mathrm{V}$ : Effect of acidotic blood reperfusion on reperfusion injury after coronary artery occlusion in the dog heart. J Cardiovasc Pharmacol 1998, 31:179-186.

25. Kitakaze M, Takashima S, Funaya H, Minamino T, Node K, Shinozak $\mathrm{Y}$, Mori $\mathrm{H}$, Hori M: Temporary acidosis during reperfusion limits myocardial infarct size in dogs. Am J Physiol 1997, 272: $\mathrm{H} 207 \mid-2078$

26. Gossett KA, French DD, Cleghorn B, Church GE: Blood biochemical response to sodium bicarbonate infusion during sublethal endotoxemia in ponies. Am J Vet Res 1990, 5 I:1370-1374.

27. Bollaert PE, Robin-Lherbier B, Mallie JP, Nace L, Escanye JM, Larcan $A$ : Effects of sodium bicarbonate on striated muscle metabolism and intracellular pH during endotoxic shock. Shock 1994, I:196-200

28. Forsythe SM, Schmidt GA: Sodium bicarbonate for the treatment of lactic acidosis. Chest 2000, I I 7:260-267.

29. Bachetti T, Pasini E, Suzuki H, Ferrari R: Species-specific modulation of the nitric oxide pathway after acute experimentally induced endotoxemia. Crit Care Med 2003, 3 I: I509-15 I4.
30. Chiang CE, Luk HN, Wang TM, Sheu JR, Ding PY: Genistein and tyrphostin AG 556 block the action potential shortening in septic shock. Zhonghua Yi Xue Za Zhi (Taipei) 2002, 65:570-579.

31. Knuefermann P, Nemoto S, Misra A, Nozaki N, Defreitas G, Goyert SM, Carabello BA, Mann DL, Vallejo JG: CDI4-deficient mice are protected against lipopolysaccharide-induced cardiac inflammation and left ventricular dysfunction. Circulation 2002 I 06:2608-26I5

32. Mutschler DK, Eriksson MB, Wikstrom BG, Lind L, Larsson A, Bergren-Kiiski R, Lagrange A, Nordgren A, Basu S: Microdialysis-evaluated myocardial cyclooxygenase-mediated inflammation and early circulatory depression in porcine endotoxemia. Crit Care Med 2003, 3 I: I 780-I785.

33. Hinshaw LB, Brackett DJ, Archer LT, Beller BK, Wilson MF: Detection of "hyperdynamic state" of sepsis in the baboon during lethal E. coli infusion. J Trauma 1983, 23:36I-365.

34. Rocha-e-Silva M, Poli de Figueiredo LF: Small volume hypertonic resuscitation of circulatory shock. Clinics 2005, 60:159-172.

35. Bone RC, Sibbald WJ, Sprung CL: The ACCP-SCCM consensus conference on sepsis and organ failure. Chest 1992, I0I:|48I-| 483.

36. Knaus WA, Draper EA, Wagner DP, Zimmerman JE: APACHE II: a severity of disease classification system. Crit Care Med 1985, | 3:8|8-829.

37. Le Gall JR, Klar J, Lemeshow S, Saulnier F, Alberti C, Artigas A, Teres D: The Logistic Organ Dysfunction system. A new way to assess organ dysfunction in the intensive care unit. ICU Scoring Group. JAMA 1996, 276:802-810.

38. Desa K, Sustic A, Zupan Z, Krstulovic B, Golubovic V: Evaluation of single intensive care unit performance by simplified acute physiology score II system. Croat Med J 2005, 46:964-969.

39. Dellinger RP, Carlet JM, Masur H, Gerlach H, Calandra T, Cohen J, Gea-Banacloche J, Keh D, Marshall JC, Parker MM, Ramsay G, Zimmerman JL, Vincent JL, Levy MM: Surviving Sepsis Campaign guidelines for management of severe sepsis and septic shock. Intensive Care Med 2004, 30:536-555.

40. Schiller NB, Shah PM, Crawford M, DeMaria A, Devereux R, Feigenbaum H, Gutgesell H, Reichek N, Sahn D, Schnittger I: Recommendations for quantitation of the left ventricle by twodimensional echocardiography. American Society of Echocardiography Committee on Standards, Subcommittee on Quantitation of Two-Dimensional Echocardiograms. J Am Soc Echocardiogr 1989, 2:358-67.

4I. Sahn DJ, DeMaria A, Kisslo J, Weyman A: Recommendations regarding quantitation in $M$-mode echocardiography: results of a survey of echocardiographic measurements. Circulation 1978, 58:1072-1083.

42. Moore EE: Hypertonic saline dextran for post-injury resuscitation: experimental background and clinical experience. Aust N Z J Surg 1991, 6 I:732-736.

43. Mazzoni MC, Borgstrom $P$, Intaglietta $M$, Arfors KE: Lumenal narrowing and endothelial cell swelling in skeletal muscle capillaries during hemorrhagic shock. Circ Shock 1989, 29:27-30.

44. Poli-de-Figueiredo LF, Cruz RJ Jr, Sannomiya P, Rocha-E-Silva M: Mechanisms of action of hypertonic saline resuscitation in severe sepsis and septic shock. Endocr Metab Immune Disord Drug Targets 2006, 6:201-206.

45. Hashiguchi N, Lum L, Romeril E, Chen Y, Yip L, Hoyt DB, Junger WG: Hypertonic saline resuscitation: efficacy may require early treatment in severely injured patients. J Trauma 2007, 62:299-306.

46. Shields CJ, O'Sullivan AW, Wang JH, Winter DC, Kirwan WO, Redmond HP: Hypertonic saline enhances host response to bacterial challenge by augmenting receptor-independent neutrophil intracellular superoxide formation. Ann Surg 2003 238:249-257

47. Coimbra R, Loomis W, Melbostad H, Tobar M, Porcides RD, Lall R, Holbrook T, Hoyt DB: Role of hypertonic saline and pentoxifylline on neutrophil activation and tumor necrosis factoralpha synthesis: a novel resuscitation strategy. J Trauma 2005, 59:257-265

48. Pantaleon LG, Furr MO, McKenzie HC 2nd, Donaldson L: Cardiovascular and pulmonary effects of hetastarch plus hypertonic saline solutions during experimental endotoxemia in anesthetized horses. J Vet Intern Med 2006, 20:|422-|428. 
49. Mathieu D, Neviere R, Billard V, Fleyfel M, Wattel F: Effects of bicarbonate therapy on hemodynmaics and tissue oxygenation in patients with lactic acidosis: a prospective, controlled clinical study. Crit Care Med I99I, 19:1352-1356.

50. Cooper DJ, Walley KR, Wiggs BR, Russell JA: Bicarbonate does not improve hemodynamics in critically ill patients who have lactic acidosis. A prospective, controlled clinical study. Ann Intern Med 1990, I I 2:492-498.

5I. Stacpoole PW, Wright EC, Baumgartner TG, Bersin RM, Buchalter S, Curry SH, Duncan C, Harman EM, Henderson GN, Jenkinson S: Natural history and course of acquired lactic acidosis in adults. DCA-Lactic Acidosis Study Group. Am J Med 1994, 97:47-54.

52. Arieff Al, Leach W, Park R, Lazarowitz VC: Systemic effects of NaHCO3 in experimental lactic acidosis in dogs. Am J Physiol 1980, 242:F586-59|.

53. Graf H, Leach W, Arieff Al: Metabolic effects of sodium bicarbonate in hyoxic lactic acidosis in dogs. Am J Physiol 1985, 249:F630-635.

54. Shapiro Jl: Functional and metabolic responses of isolated hearts to acidosis: effects of sodium bicarbonate and Carbicarb. Am J Physiol 1990, 258:HI835-1839.

55. Rhee KH, Toro LO, McDonald GG, Nunnally RL, Levin DL: Carbicarb, sodium bicarbonate, and sodium chloride in hypoxic lactic acidosis: effect on arterial blood gases, lactate concentrations, hemodynamic variables, and myocardial intracellular pH. Chest 1993, 104:913-918.

56. Ratanarat R, Brendolan A, Piccinni P, Dan M, Salvatori G, Ricci Z, Ronco Pulse C: High-volume haemofiltration for treatment of severe sepsis: effects on hemodynamics and survival. Crit Care 2005, 9:R294-302.

57. Chrusch C, Bautista E, Jacobs HK, Light RB, Bose D, Duke K, Mink $\mathrm{SN}$ : Blood pH level modulates organ metabolism of lactate in septic shock in dogs. J Crit Care 2002, 17:188-202.

\section{Pre-publication history}

The pre-publication history for this paper can be accessed here:

http://www.biomedcentral.com/1471-2334/8/50/prepub

Publish with Biomed Central and every scientist can read your work free of charge

"BioMed Central will be the most significant development for disseminating the results of biomedical research in our lifetime. "

Sir Paul Nurse, Cancer Research UK

Your research papers will be:

- available free of charge to the entire biomedical community

- peer reviewed and published immediately upon acceptance

- cited in PubMed and archived on PubMed Central

- yours - you keep the copyright

Submit your manuscript here:

http://www.biomedcentral.com/info/publishing_adv.asp
BiolMedcentral 